"Using social media to market a promotional event to SMEs: opportunity or wasted effort?"

\begin{tabular}{|c|c|c|}
\hline AUTHORS & Michael C. Cant & \\
\hline ARTICLE INFO & $\begin{array}{l}\text { Michael C. Cant (2016). Using s } \\
\text { SMEs: opportunity or wasted eff } \\
\text { 14(4), 76-82. doi:10.21511/ppm. }\end{array}$ & $\begin{array}{l}\text { rket a promotional event to } \\
\text { d Perspectives in Management, }\end{array}$ \\
\hline DOI & http://dx.doi.org/10.21511/ppm.1 & \\
\hline RELEASED ON & Wednesday, 14 December 2016 & \\
\hline JOURNAL & "Problems and Perspectives in I & \\
\hline FOUNDER & LLC "Consulting Publishing Co & Perspectives" \\
\hline & & =:- \\
\hline NUMBER OF REFERENCES & NUMBER OF FIGURES & NUMBER OF TABLES \\
\hline
\end{tabular}

(C) The author(s) 2022. This publication is an open access article. 
Michael C. Cant (South Africa)

\title{
Using social media to market a promotional event to SMEs: opportunity or wasted effort?
}

\begin{abstract}
Much has been said about the advantages of using social media in the marketing of brands and products of companies. Marketing, as we knew it in the past millennia, has changed dramatically and is evolving at a faster pace than ever. Traditional media, such as print and broadcast, are becoming more obsolete and largely replaced by social media platforms. These platforms are growing and expanding in leaps and bounds and have become potent instruments of marketing. It is up to organizations to use these platforms to market their brands, services and business, as it can have a profound effect on the success and growth. This is even truer in the case of entrepreneurs who are generally younger and more technology savvy and who use social media for all means and purposes. The purpose of this research study was, therefore, to investigate the use of social media among institutions that focus on specific events such as a business plan competition and to establish to what extent the use of these social media tools were used or effectively used to communicate the event to SMEs. A web-based self-administered questionnaire was distributed among the respondents of a business plan competition. A total of 992 useable responses were received. The findings mainly revealed that institutions that use social media in their marketing drive either do not plan properly for the use of it, or is careless in their approach to these tools. The results pointed to a large number of respondents $(55 \%)$ who were not even aware that social media tools were used in the promotion of the competition.
\end{abstract}

Keywords: social media, SME, special event marketing, marketing, usage, promotional mix elements, South Africa. JEL Classification: M13.

\section{Introduction}

Integrated marketing communication has become an established and well researched discipline during the past decades. Technology has changed the way we think about business and it has forced marketers to be more aware of these changes in order to be able to serve their markets better. One such change that has occurred is that a wide variety of digital media alternatives have become available (Koekemoer, 2014). Deciding on the most suitable means to communicate with their customers is, therefore, a critical task of management, as it impacts directly on its ability to successfully market the company and its products and services (Ume-Amen, 2011). In order to achieve this, the organization can use either traditional means such as television, radio or print or non-traditional methods, such as electronic and online media, in order to communication with customers (Ogden-Barnes, 2012).

Social media has become a popular topic for researchers and is gaining more status among businesses to use it as a marketing channel. This emphasizes the need to investigate the relevance and importance of social media in the market place, and specifically if this also applies to SMEs. The literature suggests, however, that there is a gap in the market regarding the use of social media in order to utilize the full potential it is said to have. This can primarily be attributed to a lack of criteria to guide them in achieving this goal (He \& Nguyen, 2016).

(C) Michael C. Cant, 2016.

Michael C. Cant, Professor, Department of Marketing and Retail Management, University of South Africa, South Africa.
This article focuses on the viability of using social media in marketing specific events to SMEs by institutions involved in promoting the interests of SME development. The feedback obtained from this research will serve as guidance to future use of social media to market initiatives by relevant organizations tasked with SME development.

In the remainder of this article, the context and literature review associated with this study are presented, followed by the research objectives, methodology used, as well as the findings and conclusions.

\section{Small to medium enterprises (SMEs)}

Researchers all have different definitions as to what a SME is. Cant and Wiid (2013) define an SME as: "a separate distinct entity including cooperative enterprises and non-governmental organizations managed by one owner or more, including branches or subsidiaries, if any, is predominately carried out in any sector or subsector of the economy mentioned in the schedule of size standards". On the other hand, the European Commission (2006, p. 5) defines small and medium enterprises (SMEs) as enterprises that have less than 250 employees and an annual turnover that is not more than 50 million euro per annum.

For the purposes of this article, an SME will be defined as an enterprise that is managed by an owner, or part owners, has a relatively small market share, and is managed independently (Abor \& Quartey, 2010). 


\section{The importance of SMEs}

During the past number of years, great emphasis has been placed on developing and recognizing SMEs by governments all over the world - and specifically in South Africa - as a means to decrease wealth inequalities and to improve the economy (Oni \& Faktoki, 2013). Governments worldwide are investing in SMEs for various reasons, and there are numerous institutions that focus their efforts on generating interest in SMEs and to encourage entrepreneurs to start a business.

According to the South African Department of Trade and Industry, small, micro and medium sized enterprises are responsible for $51-57 \%$ of South Africa's gross domestic profit, employ over $60 \%$ of workers in South Africa, and they are responsible for up to $80 \%$ of new jobs created all around the world (Cant \& Wiid, 2013). In South Africa, close to $91 \%$ of private businesses are classified as SMEs, with a contribution of more than $60 \%$ to employment. In Europe, it is estimated that more than 75 million employment opportunities are created by SMEs (European Commission, 2006).

Due to the importance of SMEs to any country, it is, therefore, understandable that institutions who encourage entrepreneurs to start businesses would like to focus on the ways and means that will be most effective to generate interest in their offerings and services. It is also important for these institutions to use marketing means that will prove to be the most effective. One area that has been touted as the marketing medium to use is social media. It is, however, important that the opinion of SMEs be solicited if an organization hopes to be effective in using social media in its marketing of events and competitions to generate interest in them.

\section{Defining social media}

As is the case with most terms, a myriad of definitions can be offered to explain a term. The same applies to social media for which a wide range of definitions can be found. This is partially a result of the fact that there is no singularly acceptable definition of exactly what it is, but also due to the fact that a definition offered today may be absolute in a short period, due to the continuous and rapid evolution taking place in technology, which will impact on what we call social media today. An acceptable and general definition might be:

"Social media are primarily Internet-based tools for sharing and discussing information..." (Fernando, 2012). Put another way, social media can be defined as an electronic communication medium, where people form groups with whom they share a wide range of issues, ideas, personal aspects of themselves, information of interest to them, and anything else deemed to be relevant and interesting to them.

This broad definition covers a number of tools available to marketers and is fairly inclusive of all elements that can be seen as being part of social media.

3.1. Social media categories. Social media consist of a number of different categories which can all be used in the marketing actions of institutions. These categories are briefly outlined below (Cant, van Heerden \& Ngambi, 2013).

The first category refers to communication tools. This category includes some of the more well-known social media tools and include blogs, such as Vox; websites where you can create articles which visitors can comment on; micro-blogging, such as Twitter and Tumblr; social networking, such as Facebook, Hi5, LinkedIn, MySpace, and Bebo; social network aggregation, for example, NutshellMail and Friend Feed; and events like Eventful and Meetup.com. We can also include crowdfunding sites, for instance, Kickstarter or Zopa, which facilitate funding for a business or individual.

The second category of social media is collaboration. These refer to tools that are used by many on a daily basis and include, for example, Wikipedia, which is a collaborative tool that enables many people to simultaneously update and view an online encyclopaedia. It also includes PBWorks and Wetpaint. Social bookmarking, or social tagging, is also used and include StumbleUpon and Google reader; social news which include Digg, Mixx and Reddit.

Reviews and opinions is a third category, these sites are, to some extent, similar to communication and blog sites, but there is a subtle difference between the two. Blog sites are generally not so well regarded or seen as being as authoritative as sites that specialize in being authoritative and well regarded "good sources" for information and knowledge. Quora and Yahoo Answers are examples of sites that specialize in allowing openended questions to be posed and responded to by other users in the community (Fernando, 2012). Other tools in this category include product reviews from epinions.com and MouthShut.com; business reviews from yelp.com and Community Q\&A from Yahoo Answers and Askville.

Brand monitoring is a fourth category and include tools that are, to some extent, less known, but are familiar to companies and consumer brands. Brand monitoring tools enable one to read and summarize what is being said on the web and social media 
about particular brands, people, and products against defined keywords (Fernando, 2012). Brand monitoring includes social media monitoring methods such as Attensity360 and Sysomos Heartbeat; and social media analytics such as Sysomos MAP.

A fifth category is entertainment, a tool that developed due to the advances in social media and the internet. The entertainment and gaming industry has embraced this aspect to the extent that many games are dependent on social media in order to retain and monetize players. We now find media and entertainment platforms such as Cisco Eos; virtual worlds such as Second Life and Forterra; and game sharing such as Miniclip and Kongregate.

A sixth category is media sharing or multimedia. Photography and art sharing tools include, for example, DeviantArt and Flickr; video sharing include the popular YouTube, Vimeo and Zideo; live-casting, which includes Ustream.tv, Skype and OpenCU; music and audio sharing includes MySpace Music and The Hype Machine; and, lastly, presentation sharing with SlideShare and Scribd.

The categories referred to above are but a framework and by no means exhaustive. It can be expected with the advances taking place in technology that new tools will be developed and these will find its way into marketing actions and strategies where its uses and capabilities will be optimized. It will be the responsibility of marketers to stay up to date with these developments and how to harness its potential benefits for the good of the organization.

\subsection{Social media: some prominent tools and their}

uses. There are numerous tools that can be used by marketers to promote their products and services. These are typical mediums that can be used by organizations to promote their events and services or other actions. Some of the more commonly used ones or well-known ones are briefly discussed below (Cant et al., 2013).

Facebook is a social networking website launched in 2004. It is free and registered users can add people as friends, upload photos and video, send messages and keep in touch with friends, family and colleagues. Any person above the age of 13 is allowed to become a user. From an organizational point of view, Facebook is the one place online that a company can be sure their customers and prospects are active. Building a Facebook page is a smart move for a business, as it offers the opportunity to tap into an existing community that is growing constantly. There are more than 450 million users worldwide and Facebook pages can be used to syndicate blog content, post news, share information and share multimedia content with followers. It can also be used in employer branding and recruiting.

Blogging refers to an online journal which basically anyone can do. There are more than 140 million blogs with at least a third in English. Simply put, a blog is a live website that any user can easily edit with little technical skill. Blog articles are called posts and are normally a maximum of 1000 words. Today there are numerous company blogs which has become an essential tool in the online marketing tools of organizations. It is a powerful tool for building community and from there the organization can share the content of these blogging messages with their friends - driving traffic back to the company's blog and website. This is referred to as inbound marketing and a very powerful medium to use.

Twitter is a free social networking and microblogging service that enables its users to send and read messages known as tweets. The messages are public and the organization or individual decide what sort of message they want to receive. When one combine messages that are quick to write, easy to read, public, controlled by the recipient, it is a powerful real-time means of communication. Realtime is a major advantage for individuals and businesses alike. Twitter allows organizations to communicate freely with customers on their terms and building relationships.

LinkedIn is seen as the social network for professionals or Facebook in a suit as Business week described it (Business week staff writer, 2008). This tool can be used to disseminate information in a professional way about a company's products, services and brand.

Reddit is a social news website and forum where stories are shared by the site members. There are a large number of "subreddits" and each of these focuses on a specific topic such as business, product safety, trends and so forth. Reddit site members will contribute content - and it can be organization driven - which is, then, voted upon by other members. Organizations who manage these stories well will aim to gain top position on these pages which will enhance exposure.

Pinterest is a social curation website for sharing and categorizing images found online. Pinterest has short descriptions, but the main focus of the site is on the visual elements. Clicking on an image will take you to the original source, for example, if you click on a picture of a pair of shoes, you might be taken to a site where you can purchase them. An image of a lady's bracelet might take you to the store; a picture of a car may take you to the dealership. 
3.3. Social media marketing. Social media marketing (SMM), in essence, is where a company uses established social networking tools to assist it to increase its customer base and to enhance brand exposure.

As the term indicates, it is a social media tool which is dependent on the need for social interaction of people - to provide them with content that they will feel compelled to share with others on social networks. Businesses, therefore, need to focus on ways and means to optimize these interactions. This is called social media optimization (SMO). SMO can be defined as the process or strategy that is used to attract new and unique visitors to a website. This can be achieved in various ways, for example, by linking to relevant social media links, as well as activities that promote responses and actions via Facebook, tweets, or blog posts. The use of these tools can be very effective in the marketing drive of organizations. An example is Facebook, where people or friends can like the page of the company or its brand or product, and share with their friends who open a channel for communication, marketing and networking.

The organization can track the conversations that are created through these social media sites - all in realtime. It also allows the company to get feedback from the market about their products, service and experiences. It also allows the organization to react in real-time to any comments by customers - be it positive or negative feedback. By managing social media, organizations can do a lot to promote their brand or products to a diverse audience. Internally, these social tools can also enhance the internal dynamics to address issues that may arise.

By using these social platforms, companies can solicit ideas, suggestions and comments from customers and in so doing create a presence in the marketplace, which has a wide reach and also a fairly long lifespan. This, however, will require proper management and diligence on the side of the company. It must also be noted that the integration of social media in the marketing strategy of an organization can pose challenges. Social media can very quickly lead to a something going viral if regarded as negative and thereby damaging the organization's brand and name. Employees, therefore, need to be cautioned regarding statements on the company and its products and that a certain expectation is there regarding their posts.

\section{Research methodology}

Various institutions - government and private - are constantly promoting a range of services, events and competitions to potential entrepreneurs, new and established SMEs in order to either improve their businesses, to generate interest, or to create awareness for SMEs. Various means are used to communicate these actions to the target audience, but it is not always clear if the media selected was effective or if the target audience finds the media used appropriate. The aim of the research project was to establish whether the use of social media was regarded as effective by the respondents and what their experience in this regard was.

The primary objectives of the project were to obtain feedback from the respondents regarding their perception and the value they consider the use of social media have in the marketing of institutions services and promotions based on the feedback of a specific initiative.

The study focused on a specific event, a business plan competition that was promoted countrywide, and respondents' perceptions were measured in order to evaluate the effectiveness of the use of social media in the campaign. In order to meet these objectives the following structured research process was employed.

A sample of more than 3000 entrees, were selected and a web-based survey was sent via an e-mail link. A random selection of entrees without an e-mail address was, then, selected to complete the survey via a computer assisted telephone interview (CATI).

The questionnaires that were utilized for the research project were developed and, then, translated into webbased surveys that were, then, sent to entrees. Questionnaires were pre-tested and any weaknesses in the design of the instrument were identified and corrective action was taken, thereby ensuring that the quality of the questionnaire was satisfactory.

Survey Monkey was used which resulted in the responses being captured automatically which makes accessibility to data faster. Due to the electronic nature of the data collection instrument, human error with regard to data capturing was eliminated, therefore, tracking of data capturing was unnecessary.

The data did not need to be audited, as Survey Monkey provided a token to each individual respondent via the e-mail sent out, ensuring that there were no duplicate responses. A total of 992 completed questionnaires were received and the analysis is based on these responses.

\section{Main findings of the research}

5.1. Profile of respondents. The total number of respondents who participated in the survey was 992 of which $34.3 \%$ (340 respondents) were from Gauteng, constituting the largest response rate within a province. KwaZulu-Natal made up $10.7 \%$ 
(106 respondents) of the population and the Western Cape made up 10.2\% (101 respondents). With the aim of capturing the views of a wide spectrum, the respondents varied in age. Only $3(0.3 \%)$ individuals were younger than 18 years, $26.5 \%$ (263 respondents) were between the ages of 26 and 30 and $19.1 \%$ (189 respondents) of the respondents were between the ages of 31 and 35 . Gender was distributed in the sense that $65.3 \%$ (648 respondents) of the respondents were male and
$34.7 \%$ (344 respondents) were female. The majority (80.4\%; 798 respondents) of the entrees and respondents in the survey were black.

5.2. Research findings. The respondents were specifically asked if they were aware if the specific institution made use of social media to promote the Business Plan Competition. Respondents could indicate "Yes", "No", or "I don't know". The results are shown in Figure 1.

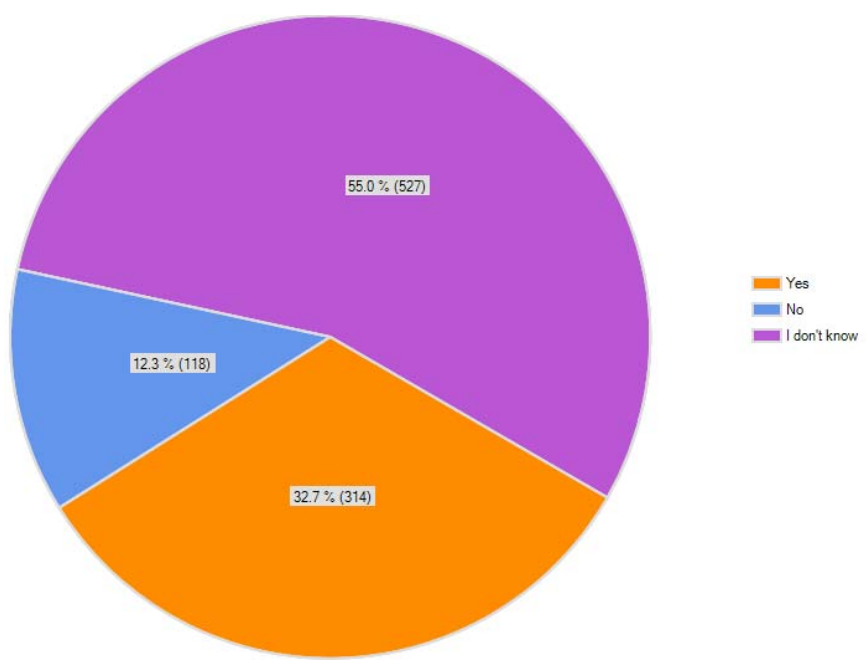

Fig. 1. Did the institution make use of social media? $(n=959)$

From Figure 1, it is clear that only $32.7 \%$ of respondents (314) were aware that the institution made use of social media, while $12.3 \%$ of the respondents indicated that the institution did not make use of social media. A large number of respondents (55\% or 527) did not know whether the institution used social media or not. From these responses, it would seem that much will have to be done to improve on the effectiveness of social media campaigns if these are to be used in the marketing of specific events.

Respondents were asked to indicate the social media platforms they were exposed to that promoted the Business Plan Competition. Respondents who answered this question could select more than one of the options provided. Figure 2 illustrates the findings.

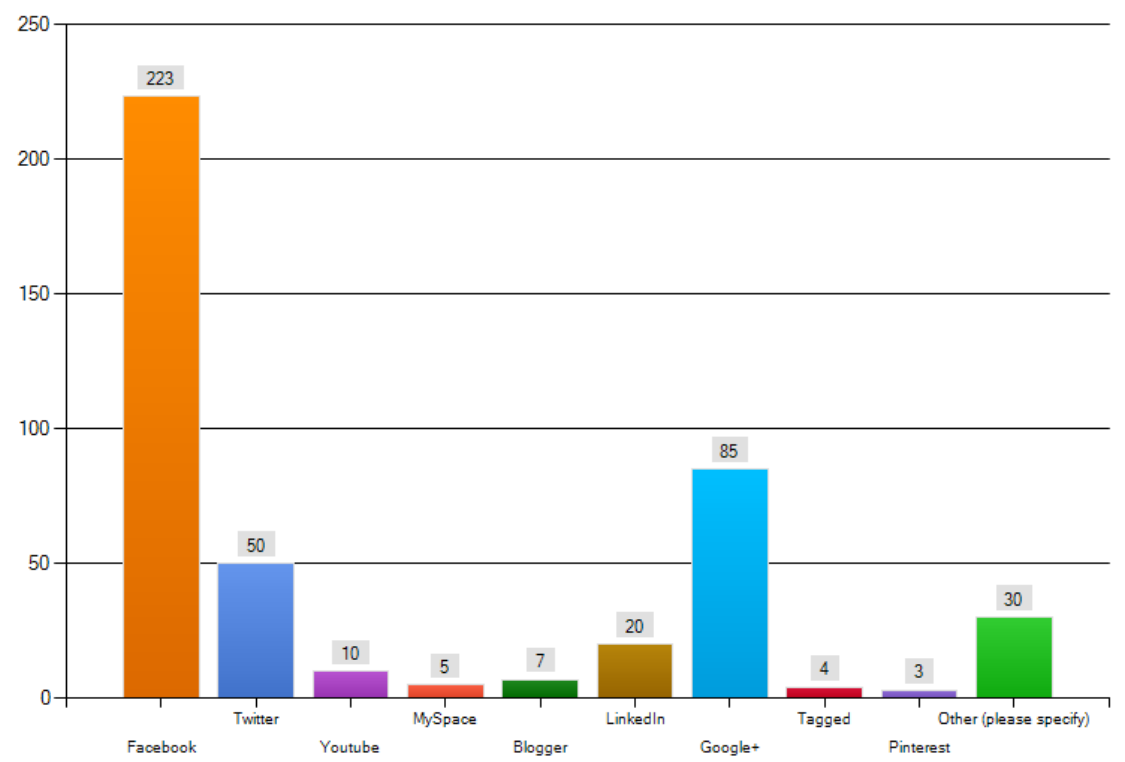

Fig. 2. What type of social media platforms were you exposed to that promoted the Business Plan Competition? $(n=313)$

Note: total responses does not equal $\mathrm{n}$ as this question was a multiple-choice multiple-response question. Percentage was calculated using the frequency count per category divided by $n$. 
From the figure above, it is evident that Facebook was the most prominent social media platform, with $223(71.2 \%)$ of respondents indicating that they had seen information regarding the Business Plan Competition on Facebook. Google+ was the second most prominent platform, as indicated by respondents that they were exposed to with 85 (27.1\%) respondents indicating that they had seen information regarding the competition through this social network. It should, however, be noted that Google+, a social network, could have been confused with Google the search engine. The responses serve as an indication as to the more suitable or appropriate social media to use when marketing specific events or initiatives.

The "Other" option that respondents indicated, are indicated in Table 1 below:

Table 1. "Other" social media platforms respondents were exposed to $(\mathrm{n}=30)$

\begin{tabular}{|l|c|c|}
\hline \multicolumn{1}{|c|}{ Category } & Percentage & Frequency count \\
\hline Email & $6.7 \%$ & 2 \\
\hline Internet & $10.0 \%$ & 3 \\
\hline
\end{tabular}

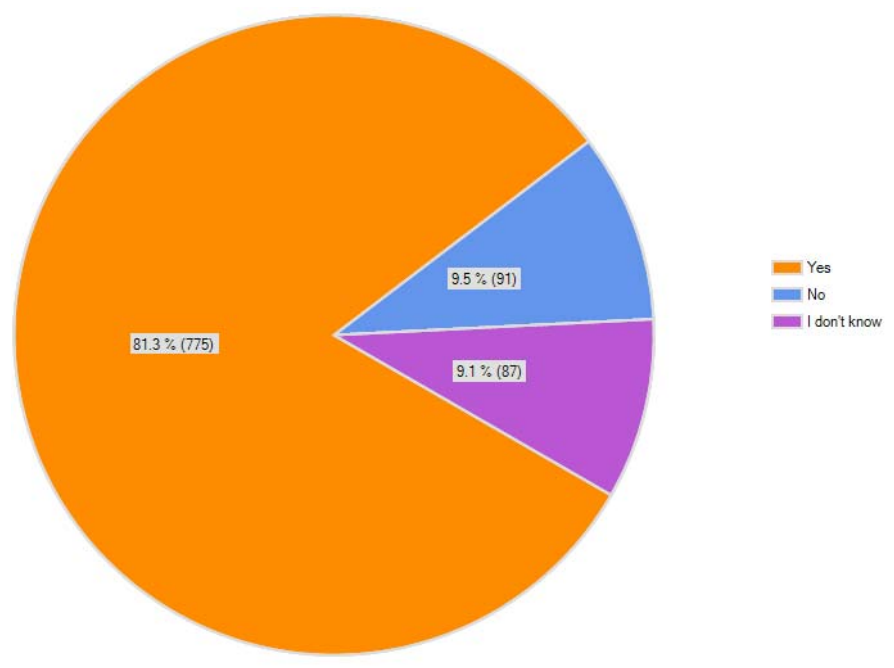

\begin{tabular}{|l|c|c|}
\hline Newspaper & $16.7 \%$ & 5 \\
\hline None/no & $26.7 \%$ & 8 \\
\hline Other & $6.7 \%$ & 2 \\
\hline Phone & $6.7 \%$ & 2 \\
\hline Radio & $16.7 \%$ & 5 \\
\hline Website & $20.0 \%$ & 6 \\
\hline Word of mouth & $6.7 \%$ & 2 \\
\hline
\end{tabular}

Note: total responses does not equal $\mathrm{n}$, as this question was a multiple-choice multiple-response question.

The majority of the respondents indicated that they were exposed to the institutions website $(17.1 \%)$, followed by radio $(14.3 \%)$ and newspapers $(14.3 \%)$. The fact that a number of responses included more traditional media and not social media platforms shows that there is a lack of understanding what social media is among some respondents.

Respondents were asked whether they consider social media platforms to be an effective tool with which to communicate information with and specifically for something such as a business plan competition. The response to this question is shown in Figure 3.

Fig. 3. Respondents' perception of the effectiveness of the social media platforms $(n=953)$

From Figure 3, it can be seen that $81.3 \%$ (775) of the respondents felt that social media platforms were a highly effective means whereby these types of events can be marketed, compared to $9.5 \%$ (91) who said they did not think these platforms were very effective. A further $9.1 \%$ (87) did not have an opinion about its effectiveness. It is encouraging to see the positive response and opens the door for opportunities in future to expand on this medium.

The responses of the respondents regarding the marketing of the business plan competition in general generated interesting statistics.

The internet $(39.1 \%$; 378), the institutions website $(32.6 \%$; 315) and newspapers/magazines (23\%; 222) were the most popular platforms from which entrees were made aware of the competition.
The internet was the main source of information regarding the competition for respondents from and $55.8 \%$ (539) of the respondents indicated that they were exposed to the competition mostly through the internet, while $43.9 \%$ (424) of respondents indicated that they were exposed to the institutions website as the source of information throughout the competition. A further $33.2 \%$ (321) of the respondents indicated that they used email as a source of information throughout the competition.

In total, $89.5 \%$ (863) of the respondents indicated that they had accessed the institution's website during this period, and of those respondents who had accessed the website, $90.3 \%$ (776) indicated that they felt the website was user-friendly. 
As shown, 55\% (527) of respondents indicated that the institution did not make use of social media. This may be attributed to the fact that the institution placed social media within the PR and mobilization section, and from the research finding, it became clear that this platform was not well implemented. Future competitions should ideally enhance communication to entrees with regards to available social media platforms and make it a focal point in the promotion of such a competition.

\section{Conclusion}

From the findings, it is clear that social media as a marketing tool was not effectively utilized in the marketing of the competition. There may be a number of reasons for this and one being that there is not a clear understanding as to what social media marketing is from the institution, how best to utilize it, how to manage it or which media is available. The low level of awareness of social media used and the placement of the social media actions in the total planning process would seem to be indicative of the perceived value of this form of marketing.

As social media is becoming an important phenomenon in individuals' lives and many have access to social media sites, such as Facebook or Twitter, organizers should focus more on the use of these media in future and ensure that this fact is communicated to the market when running the competition.

The majority of respondents also indicated that they would like institutions to make more use of social media methods and as virtually everybody have a mobile phone, it will enhance the reach of these efforts to market such events.

\section{References}

1. Abor, J. and Quartey, P. (2010). Issues in SME development in Ghana and South Africa, International Research Journal of Finance and Economics, 39, pp. 218-228.

2. Business week Staff writer. (2008). Facebook in a suit: LinkedIn launches Applications Platform. Business week, 28 October 2008.

3. Cant, M.C. and Wiid, J.A. (2013). Establishing the challenges affecting South African SMEs, International Business \& Economics Research Journal, 12 (6), pp. 707-716.

4. Cant, M.C., Van Heerden, C.H. and Ngambi, H.C. (2013). Marketing Management: A South African Perspective. $2^{\text {nd }}$ edition. Cape Town, South Africa: Juta \& Co.

5. European Commission. (2006). The new SME definition. User guide and model declaration. Available at: http://ec.europa.eu/enterprise/policies/sme/files/sme_definition/sme_user_guide_en.pdf.Accessed on 2014-05-22.

6. Fernando, P. (2012). Social Media and its Uses. Available at: https://www.liquidlight.co.uk/blog/article/socialmedia-and-its-uses/. Accessed on 17 May 2016.

7. He, A.Z. and Nguyen, N.L. (2016). The multiple linear regression model for the quality of word-of-mouth on Facebook, The International Journal of Business \& Management, 4 (3), p. 336.

8. Koekemoer, L. (2014). Marketing Communications: An integrated approach. Cape Town: Juta \& Co.

9. Ogden-Barnes, S. (2012). Decision-making in retail marketing: The end of gut feel? White paper prepared by Deakin University and Pitney Bowes Software. Available at: http://www.pitneybowes.com.au/software/DecisionMaking_in_Retail_Marketing_Thought_Leadership_Paper_Pitney_Bowes_Software_Australia.pdf. Accessed on 2016-05-17.

10. Oni, O. and Faktoki, O. (2013). Customer satisfaction and loyalty to Small Township retail stores in Mankweng, Limpopo Province, South Africa, Journal of Economics, 4 (2), pp. 83-88.

11. Ume-Amen, M. (2011). Media Influence on Marketing Communications, Interdisciplinary Journal of Contemporary Research in Business, April 2011.

12. Worku, Z. (2013). Analysis of factors that affect the long-term survival of small business in Pretoria, South Africa, Journal of Data analysis and information processing, 1, pp. 67-84. 